\title{
The Balanced Scorecard Management of New Paradigm Agriculture in Tumbon Sankrang, Sankampang District, Chiang Mai Province, Thailand.
}

\author{
TAIEN LAYRAMAN \\ Business Faculty, Payap University. \\ Email: taien_1@ payap.ac.th \\ Tel: +66813096326 \\ APICHA INSUWAN \\ Accountancy and Finance Banking Faculty, Payap University. \\ Email: apicha@payap.ac.th \\ Tel: +66908954599
}

\begin{abstract}
This research tittle "The Balanced Scorecard Management of New Paradigm Agriculture in Tumbon Sankrang, Sankampang District, Chiang Mai Province" is qualitative research. The purpose of this study is to survey the implementation of agriculture the group, develop the balanced scorecard concept and also to evaluate this paradigm into practice by using par-study method between both the researcher and agriculture members. Data was collected by focusing this member and also target market using a balanced scorecard process. This research result was a benefit for group implements follow by the balanced scorecard concept including financial perspective, customer perspective, internal process perspective and learning and growth perspective. This result provided the group implement composed the strategy analysis, setting their missions, vision, and management. This agriculture aimed 2 projects and 2 activities which they able to implements. The researcher proposed suggestion that this group should be managing their group rely on the continuity of the accounting system and financial system or set the fundraising for their group and also developing product packaging which suitable for the new target customer, improve marketing channel by using social network marketing strategy. Moreover, the Sankrang Municipality should use more networking channels and support.
\end{abstract}

Keywords: Balanced Scorecard, Management, New Paradigm Agriculture, Chiang Mai Province, Thailand.

\section{Introduction}

Sankrang Sub-district, Sankampang District in Chiang Mai Province, Thailand is divided into 7 villages, in 2014, with a population of 7,764 people, including 3,487 men and 4,277 women, within 3,143 households in 5,495 rai, housing 3,820 rai, agricultural area 864 rai. There is about 300 rai of farmland. The majority of the population are general contractors and employees of private companies. This area like other sub-district in Thailand is administrated by the president of Sankrang sub-district municipality which has seen the obstruct with members in their sub-district who are looking for a stable career to increase the income and better living status of the members in the district. Therefore, their administrator has a strategy to promote and develop a career for members in various projects. Because of the traditional vegetable growing, farmers need to use the necessary production factors for cultivation such as fertile soil areas, sufficient amount of freshwater. 
However, the Sankrang sub-district council members are also interested in activities of the vegetable production project because it is a part of the way to reduce members' household expenses. There are enough vegetables for family consumption and can manage daily life for more Sankrang sub-district members considered that agriculture would allow members to spend time stay at home with family members and relatives.

At present, members' namely "The modern agricultural group" of Sankrang sub-district Sankampang District, Chiang Mai, Thailand has a total of 30 households with sold products to target customers, general consumers in Sankrang sub-district, restaurants in Sankampang district, etc. The needs of target customers with the number of productions of group members at a balanced level may tend to increase slightly whether the group has guidelines for marketing promotion.

The concept of balanced scorecard management is a management concept that supports practitioners to reduce their role in operational aspects not only focus on profits, but focus on balanced performance in every perspective whether it is a financial perspective, a customer, an internal process, and learning and growth. If any group or organization has adopted a balanced scorecard management approach in practice, it may allow the group to continue creating value and long-term advantages.

The goal of this research is to find a balanced management approach which this group will be able to operate according to the strategy map that is suitable for the context of the modern farmer's group, Sankrang Sub-district, Sankampang District, Chiang Mai Province, Thailand by group members participating in the determination and considering all aspects of group management.

\section{Literature Review}

David Norton, management consultants, according to a research study when the American stock market faced a problem in 1987, both found that most businesses in America during that time focused on targeting and performance indicators by a focus on the financial perspective.

Thus, the company enable to set up an action plan that focuses on reducing costs, increasing sales that affect the internal management process and production activities, operations in various parts, especially the customer perspective. The business also reduced interest to customers, focus on saving more than balance. Kaplan and Norton, therefore, offer a balanced scorecard (BSC) management approach to solve this problem.

By managing this balance is the system or process of administration that relies on the determination of Key Performance Indicator (KPI) that helps the operation of the business to be unified. The business will have to define KPI to be used as a criterion for evaluating the effectiveness of operations (Pasu Decharin, 2005, p. 20).

Balanced Scorecard (BSC) means determination of indicators for organizational management by considering various aspects to complete all aspects for the administration and the operation is consistent in the same direction which various views that includes a financial perspective, a customer perspective, an internal process perspective, and a perspective learning and growth perspective as shown in figure below. The business concept of balanced management (BSC) is applied in Asia countries such as Japan, and Thailand for over 10 years (Kritsanee Mahawirun, 2003, pp. 28 - 33).

Balanced Scorecard (BSC) is an important part of the strategic plan that the business defined as indicators by considering the vision and mission of the business and then considering balanced scorecard management as an important part of the strategic plan in which the business will be able to perform its operations following that indicator. The organization of this research group will determine the project to support the strategy as shown in figure 1 below. 


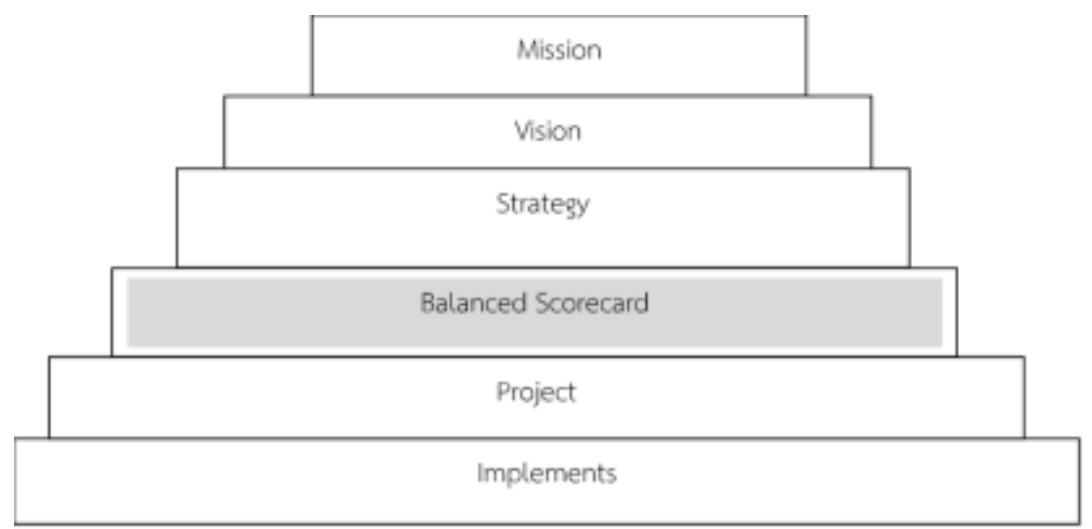

Figure 1 The relative of business strategy into the Balanced Scorecard concept

Adapted from: Nopadol Rompho, (2014, p. 123)

From figure 1, Balanced Management (BSC) is the approach that comes from considering the strategic plan of the business. The management team should first clearly define the strategic when processing this balanced management. The process before bringing balanced scorecard into practice the management team should define a support project that is consistent with indicators. Therefore, formulating balanced management.

The business must be defining KPIs so that management can be balanced the perspective of management to cover all perspectives related in operations in order not to carry out various activities focus on only one view. According to the key principles of balanced management, an important view that must be taken into account is the indicators of balanced management as shown in figure 2 below.

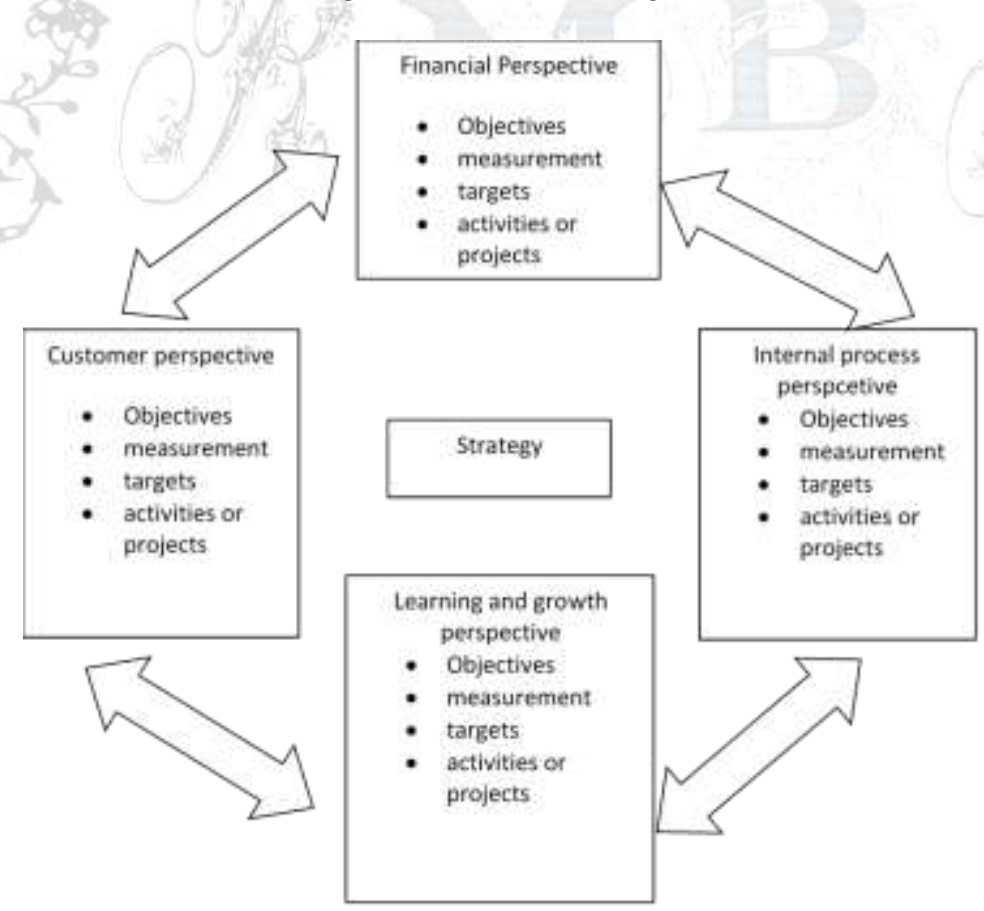

Figure 2 The concept of the balanced scorecard approach Adapted from: Robert S. Kaplan and David P. Norton, (1996, p.76) 


\section{Research Questions}

The main problem of research is how such an administrative style of modern agriculture groups, Sankrang Sub-district, Sankampang District, Chiang Mai Province should be and the researcher exams sub-research problems as:

1. What should the financial perspective of the group be?

2. What should the customer perspective of the group be like?

3. What should the internal process perspective format within the group?

4. What should the learning and growth perspective of the group?

\section{Research Objectives}

To evaluate the strategic implementation of the modern agriculture groups Sankrang Sub-district, Sankampang District, Chiang Mai Province, Thailand by using Balanced Scorecard model.

\section{Theoretical Framework}

Which Balanced Scorecard (BSC) involve with balanced factors as mention above, this research study framework is divided into 3 parts as shown in figure 3 below.

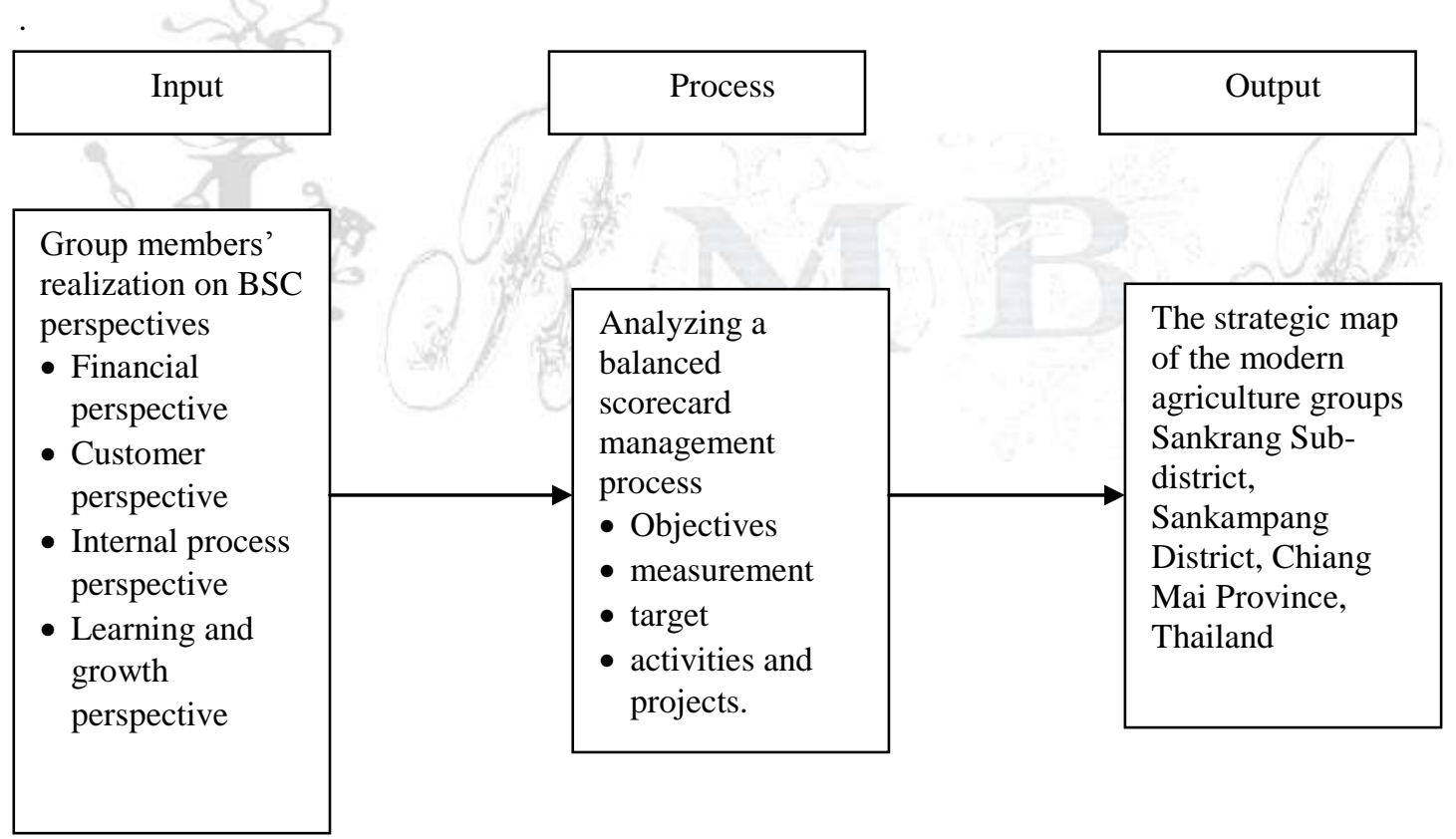

Figure 3 The conceptual framework of this research

Part 1 Input factors are data related to balancing management from previous research, the researcher realized that data should be collected in by asking from the practitioner is a member of the modern agriculture group to get all the information and all related views on the needs of consumers or target customers and questioning the facts.

Part 2 Processes are steps that researchers and group members must cooperate within developing a balanced group management process and evaluating the implementation of strategies into action to be consistent with the concept, theory and application of balanced management concepts applied modern agricultural members must participate in determining various elements those together. 
Part 3 The output of balanced management is a balanced management model of modern agricultural groups which is derived from the concept of synthesis of relevant research and found that determining the appropriate strategy map for members of the modern agriculture group must participate and understand. The guidelines and implementation of the strategy map to measure the performance of the group.

\section{Research Methodology}

This research is qualitative research with participatory action research (PAR). The objective is to study the operating conditions of the modern agriculture group, develop a balanced group management process and evaluate strategy implementation towards a balanced management practice of modern agricultural groups, Sankrang Sub-district, Sankampang District, Chiang Mai Province, Thailand based on the following research methods.

\section{Population and Sample Size}

The population used in research can be divided into 3 groups:

Group 1, members of the modern agricultural group that have been trained to support vegetable production under the housing conditions from Sankrang Sub-district Municipality, Sankampang District, Chiang Mai, Thailand. There are 7 villages in Chiang Mai, 3,143 families. There are 30 group members. The researcher collects performance data from all population.

Group 2: Coordinator and technology transfer center staff local are administrative organization level at Sankrang Municipality, Sankampang District, Chiang Mai Province, Thailand.

Group 3: Target customers of the modern farmer group which is the population in Sankrang Sub-district, totaling 7,764 people.

Sample Size from all 3 groups of population related to the collection of research data. The research team has defined the sample group as follows.

Group 1: Members of the modern agriculture group a total of 30 cases were collected from a sample of cooperation found that all group members cooperate very well enabling the research team to collect data for the entire population 100 percent.

Group 2: Coordinator and technology transfer center staff local are administrative organization level at Sankrang Municipality, Sankampang District, Chiang Mai Province, Thailand. There is only 1 person responsible for the agency and cooperate very well. Therefore, the research team can collect this group of information for the whole population.

Group 3: Target customers of a new generation of farmer groups that are populated in Sankrang Subdistrict, totaling 7,764 people. Therefore, the size of the sample group is determined by calculating the sample volume using Taro Yamane at the error level $=0.05$. Equal is 380.40 from the formula. By doing convenience sampling to provide answers, the target customers represent the population in Sankrang Subdistrict and make it more reliable. The researcher will collect data from 400 customer groups.

\section{Data Analysis and Result}

Most of the modern farmer member is male (70\%) and female (30\%). The majority age of farmer groups is over the age of 50 years, they began and joint agricultural group not more than 5 years. Currently, the research results found that most farmers grow a Japanese's cucumber and such any kind of northern local vegetables. 
The research team gathered basic information about the performance of the modern agricultural group, Sankrang Sub-district, Sankampang District, Chiang Mai Province, Thailand which is related to the management perspective in 4 areas including a financial perspective, a customer perspective, an internal process perspective, and a perspective on learning and growth by using in-depth interviews and showing the data using. The management perspective of the 4 areas that are as follows.

The financial perspective of the modern farmer's group, Sankrang Sub-district, Sankampang District, Chiang Mai Province, Thailand in the past, most of the work has been done to use worthwhile resources can translate to the highest level followed by the control of production costs and can translate to the highest level operate to have circulating investments to the highest level and operate to maximize profit into the highest level. The customer perspective of the modern farmer's group, Sankrang Sub-district, Sankampang District, Chiang Mai Province, Thailand, most of the past operations allows customers buying more products show the result as the highest level followed by the expansion of the customer base can translate to the highest level operate the product to meet the needs of customers and highest level and work to produce products meet the needs of target customers can significant to the highest level.

The internal process perspective of the modern farmer's group, Sankrang Sub-district, Sankampang District, Chiang Mai Province, Thailand, most of the past operations continues to maintain good relationships within the group show result into the highest level and working for a new farmer group play a role in determining the price of products interpreting the results at the highest level equally, followed by working for members within the group to exchange and learn together at all times to the highest level and work to improve coordination in the group can translate to the highest level. The learning and growth perspective of the modern farmer's group, Sankrang Sub-district, Sankampang District, Chiang Mai Province, Thailand, in the past, most of them worked on agricultural skills development implementing modern plant improvement equipment operating for the middle ridge is the center of modern vegetable cultivation interpret. The results at the highest level equally, followed by the operation of adding new members of agricultural groups is significant into a high level.

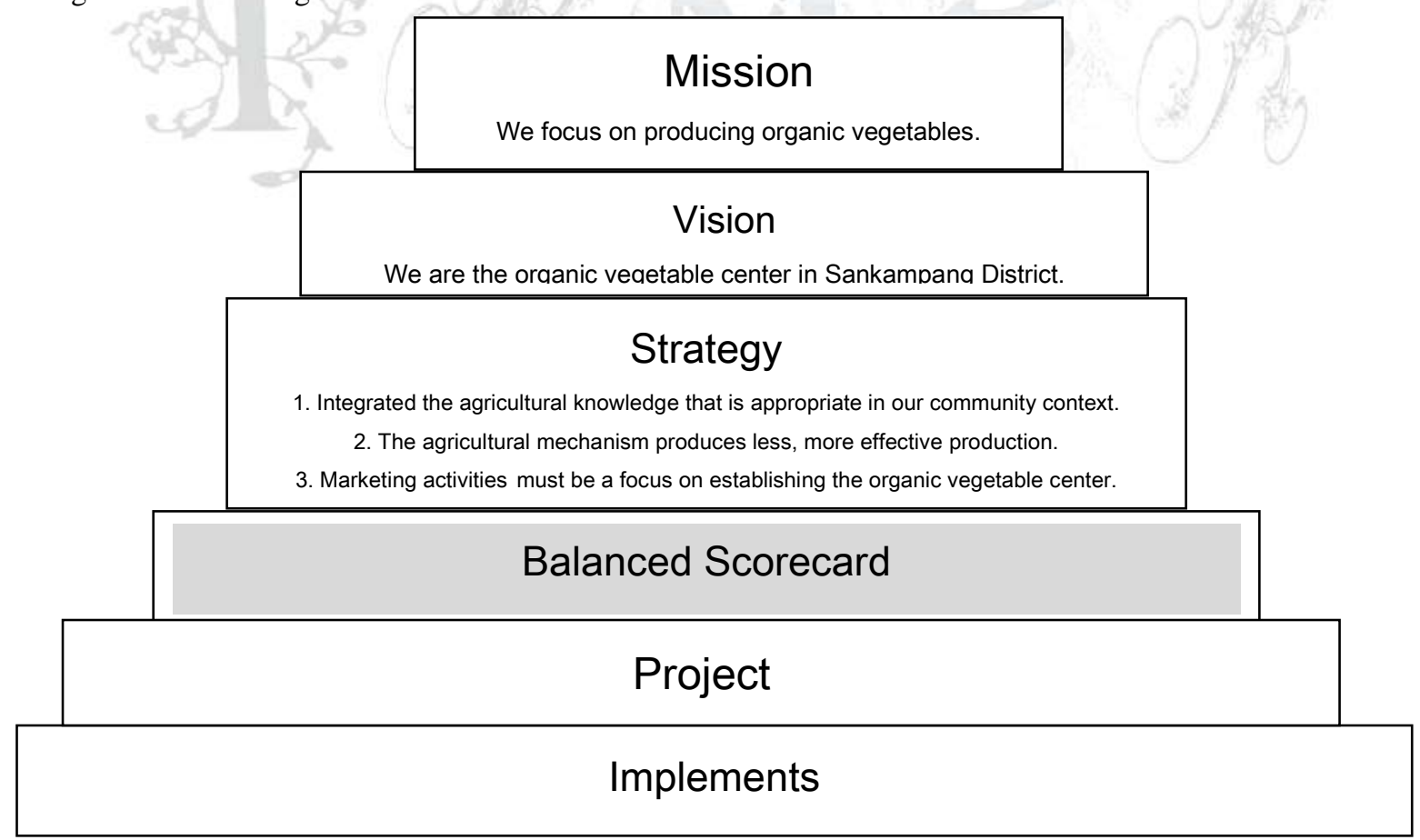

Figure 4 The relative of business strategy into the Balanced Scorecard concept of the modern agriculture groups Sankrang Sub-district, Sankampang District, Chiang Mai Province, Thailand. 
The research team and group members have jointly conducted a strategic analysis of the operation from the review of the activities of the modern agricultural group, Sankrang Sub-district, Sankampang District, Chiang Mai Province, in the past, since the group's inception until now. By considering the environment related to the operations of the modern agriculture groups both internal and external environments, assess the weaknesses, strengths, opportunities and obstacles. The research team and group members participated in determining the mission, vision and strategy of the group from considering the opportunities for future growth. The commitment that group members must create a guideline for the management of the group by considering the possibility database in the past and activities that can be conducted in the future. Therefore, defines the mission, vision and strategy as above in figure 4.

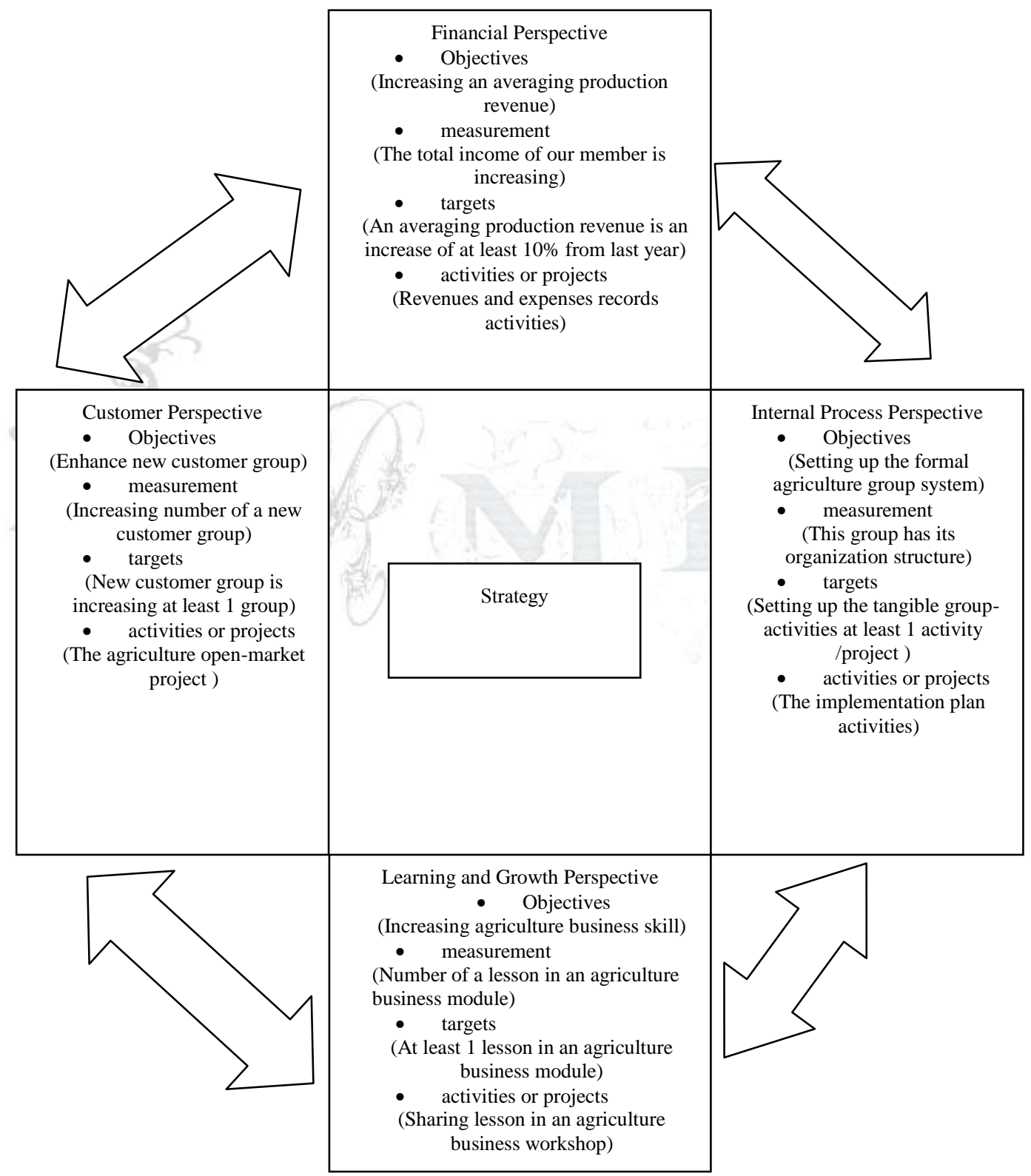

Figure 5 The balanced scorecard approach of the modern agriculture groups Sankrang Sub-district, Sankampang District, Chiang Mai Province, Thailand. 
The agriculture group members and the researcher team collected the 4 balanced scorecard perspectives; a financial perspective, customer perspective, internal process perspective and learning and growth perspective, by using the participatory action research. The result that is appropriate into our community context as shown in figure 5 above.

\section{Discussion}

Analyzed data from this agriculture group, the research discussion is divided into 3 sessions as below.

1. The operational situation of the modern agriculture groups Sankrang Sub-district, Sankampang District, Chiang Mai Province, Thailand

From this research result, the researcher and agriculture member aim to use the balanced scorecard concept are starting with concentrate into evaluation the previous implementation of our group as accordance with Suchaya Posayanan (2007) which confirm us that the strategic map should start with the evaluation their operation situation. The previous research (Suchaya Posayanan, 2007) also using the strengths, weaknesses, opportunities, and threats analysis (SWOT Analysis) explained the operation activities of her object research, in contrast, directly focused on BSC only without using the environmental analysis then effected into their research misunderstood the exactly their problems and situations. Thus, the sample size of those research avoidance the balanced scorecard concept as accordance with Noppadon Rompho (2005) found that the fewer sample sizes do not understand the concept of the balanced scorecard, the more problems with the research analysis process.

Nevertheless, our research started with a discussion on the concept of the balanced scorecard theory until the sample group received the clear knowledge method, then the researcher and the agriculture group members applied this theory in implementation. This process made the research collected by using participatory action research. The result that this research conclusion was related and balanced. The agriculture group can apply this concept into the implementations and they can set up their strategy map as same as both the research of Dulairat Buoyos (2011) and Panithan Chaimongkol (2009) were focused on the benefits of the operational situation evaluation before handle the participatory action research within the sample group.

However, the research of Achirason Mayan (2011) mentioned the best research methodology to explore the balanced scorecard should have been confirming the perception of all administrative members or other stakeholders. As a result, this research collected the perception of both the group members and their customers who located in Sankrang permission by their president. Everyone prefers to participate with the researcher and then the research can conclusion.

2. The participatory action research of new paradigm agriculture in Tumbon Sankrang, Sankampang District, Chiang Mai Province

The research procession in this study is a part of developing participatory action research development which the researcher and agriculture group members in Tumbon Sankrang, Sankampang District, Chiang Mai Province were using Deming model (Deming W. Edwards, 2000) which was main mechanism research study as same as Songsak Thungchan (2016) using the Deming model applied into his research study in Mahasarakham Learning Park, "To the learning organization it is reliable using a balanced scorecard." He was divided research method into 3 stages; first, to study the current situation, problem and background of the organization, second stages, to set up the development model of Mahasarakham Learning Park applied the balanced scorecard, and final stage, the exploratory strategic map of the balanced scorecard. Like our research, the researcher and agriculture group members set up the theoretical framework as 3 parts; input, process and output. 
3. Transformation the strategic map results in the new paradigm agriculture in Tumbon Sankrang, Sankampang District, Chiang Mai Province, Thailand.

The research result explored using the participatory action research found that the agriculture group member received the strategic plan including 2 projects and 2 activities from the analysis result and recognition in details between the researcher and group members, then, those projects and those activities response into the strategic balanced scorecard model. Moreover, the members can implement themselves directly. Contrast with Manat Wongsrikaew (2010) studied "The study of satisfaction in using deposit business services with Balances Scorecard technique: case study of Government Saving Bank, That Phanom Branch, That Phanom District, Nakhon Phanom Province, Thailand was surveyed only customers side and missing other perspectives, then, that research denied into implementation. The research also agreed and suggested the one who applied the balanced scorecard into the research has to concern the context of those organizations.

\section{Conclusion}

The research team has observed from this research that is consistent and a guideline to suggest the use of research results to practice for various groups, divided into 3 groups, namely community members, modern agricultural groups, Sankrang Sub-district coping Chiang Mai Province, Thailand, the executive group and Sankrang Sub-district municipality officer Sankampang District, Chiang Mai Province, Thailand and other community farmer's groups with similar contexts as follows.

1. Sankrang Sub-District Community Member, Sankampang District, Chiang Mai province is distinguished by informal grouping. Due to the status of group members being relatives who live in nearby areas, therefore, has a culture of mutual support when relying on cooperation in operations always receive cooperation. However, the characteristics of society in Sankrang Sub-district, Sankampang District, Chiang Mai Province, Thailand is a way of life in a city society group members connect with social networking systems but there is still a tendency to rely on municipal officials as a mainstay in determining direction administration within the group resulting in the determination of the mission, vision and strategy in accordance with the direction of the municipality may affect the practice that requires constant effort.

2. Sankrang Sub-district Municipality, Sankampang District, Chiang Mai Province, Thailand effective and have a significant influence on the operation of group members, as most municipal officials are personnel with good relationships with the group members any influence that the staff has presented to the members is beneficial to the management and the municipality's budget will affect the group member's action plan in the same direction.

3. Other community farmer's groups that can implement the same research process should be a farmer group that members have continuous due to the research process that will result in efficiency and effectiveness, this time requires a continuous operation to achieve good performance. Members must join the process from the beginning observed in this research members must participate in the planning process, evaluation of projects and activities. Therefore, the research team can collect summary data as results. If some members lack cooperation in one activity, it may result in continuity and the results that are expected to be received later.

\section{References}

Abdel-aziz Ahmad Sharabati and Saed Jamal Fuqaha. (2014). The Impact of Strategic Management on the Jordanian Pharmaceutical Manufacturing Organizations' Business Performance. International Review of Management and Business Research. 3(2). 668-687. 
Achirason Mayan. (2011). Factor affecting success in administration applying balanced scorecard principle of municipality, Chumphon province. Phetchaburi: Phetchaburi Rajabhat University.

Ching-Kuei Kao and Lixu. (2017). Study on the Performance Measurement of Taiwan Railway Service Quality through Grey Relational Analysis. International Review of Management and Business Research. 6(2). 655-668.

Dulairat Buoyos. (2011). The possibility of implementing the balanced scorecard in Nathawi Sub-district Admistrative Organization, Nathawi District, Songkhla Province. Khon Kan: Khon Kan

Edwards Deming. (2000). Out of the Crisis. MIT Press. Cambridge. Massachusetts.

Ehab Nazmi Ibrahim and Radwan El-Anati. (2017). Measuring the Extent of Bahraini Banks Implementation of the Balanced Scorecard in Evaluating Employees' Performance and the Factors that Affecting It. International Review of Management and Business Research. 6(3). 1262-1273.

Kritsanee Mahawirun. (2003). Balanced Scorecard management concept. Journal of SPOT Newsletter, $16(155), 28-33$.

Manat Wongsrikaew. (2010). The Study of Services Satisfaction in Depositing with the Bank by Using Balanced Scorecard Technique: A Case Study of That Phanom Government Savings Bank Branch, Tatphanom District of Nakhon Phanom Province. Ubon Ratchathani: Ubon Ratchathani Rajabhat. University.

Nopadol Rompho. (2014). Organizational performance measurement. Bangkok: Thammasat University Press.

Panithan Chaimongkol. (2009). An appropriateness of the balanced scorecard model in evaluating the village and urban community fund in Tambon Cho. Chiang Mai: Chiang Mai University.

Pasu Decharin. (2005). Balanced scorecard. Imperative knowledge = Implementing balanced scorecard. Bangkok: Faculty of Commerce and Accountancy Chulalongkorn University.

Robert S. Kaplan and David P. Norton. (1996). Using the Balanced Scorecard as a Strategic Management System. Harvard Business Review. 76,75-85.

Songsak Thungchan. (2016). Guidelines for the development of Maha Sarakham Learning Park to the learning organization It is reliable Using a balanced scorecard. Educational Research Journal Faculty of Education SWU. 10(1). 56-69.

Suchaya Posayanan. (2007). The Implementation of a Balanced Scorecard (BSC) to Public Organizations: A Comparative Case Study of Local Government Organizations in Phitsanulok. 